\title{
Is There an Optimal Antiplatelet Strategy after Gastrointestinal Bleeding in Patients with Coronary Artery Disease?
}

\author{
Stephen J. Pickett ${ }^{\mathrm{a}}$ Glenn N. Levine ${ }^{\mathrm{a}}$ Hani Jneid $^{\mathrm{a}}$ Deepak L. Bhatt ${ }^{\mathrm{b}}$ \\ Vijay Nambi ${ }^{\mathrm{a}}$
}

aMichael E DeBakey Veterans Affairs Hospital, Baylor College of Medicine, Houston, TX, USA; 'brigham and Women's Hospital Heart \& Vascular Center, Harvard Medical School, Boston, MA, USA

\section{Keywords}

Antiplatelet therapy - Stable coronary artery disease .

Gastrointestinal bleeding

\begin{abstract}
Gastrointestinal bleeding after percutaneous coronary intervention $(\mathrm{PCl})$ is a not too uncommon clinical situation and is associated with high morbidity and mortality. After initial treatment, a number of clinical decisions must be made weighing the risks of ischemic events and future bleeding. In particular, healthcare providers must carefully balance the effectiveness of antiplatelet therapy in the secondary prevention of coronary events, primarily future spontaneous myocardial infarction and stent thrombosis, against the risk of major, most commonly gastrointestinal bleeding. The first question is whether a dual antiplatelet therapy strategy is required or if a single antiplatelet agent will suffice. Then, if a single antiplatelet agent is adequate, which agent should be continued. Although there is some guidance to answer some of these questions, there are inadequate evidencebased data for others. Below, we review the various considerations and summarize our approach and rationale to manage patients who had gastrointestinal bleeding after $\mathrm{PCl}$.
\end{abstract}

(c) 2021 S. Karger AG, Basel

\section{Introduction}

\section{Clinical Vignette}

A 63-year-old male with a past medical history of hypertension and coronary artery disease who underwent a percutaneous coronary intervention (PCI) of his first obtuse marginal branch of the circumflex coronary artery with a $2.5 \mathrm{~mm} \times 15 \mathrm{~mm}$ second-generation everolimuseluting stent 12 months ago for a non-ST segment elevation myocardial infarction (MI) presented to the emergency room with melena. The patient was hemodynamically stable, and physical exam was notable only for epigastric tenderness. His current medications included aspirin 81 $\mathrm{mg}$ daily, clopidogrel $75 \mathrm{mg}$ daily, lisinopril $10 \mathrm{mg}$ daily, metoprolol tartrate $25 \mathrm{mg}$ twice daily, and atorvastatin 80 $\mathrm{mg}$ at night. Due to the concern for upper gastrointestinal (GI) bleeding, an upper GI endoscopy (EGD) was performed and showed an ulcer in the gastric body with stigmata of recent bleeding. Biopsies were taken from the gastric mucosa to evaluate for Helicobacter pylori and indicated no evidence of infection. The patient was diagnosed with aspirin-induced gastric ulcer and was started on a therapeutic course of a proton pump inhibitor (PPI). The patient presented to the cardiology clinic the following week seeking recommendations for antiplatelet therapy. 
Table 1. Comparison of DAPT and PRECISE DAPT risk scores $[17,18]$

\begin{tabular}{|c|c|c|}
\hline \multicolumn{2}{|l|}{ DAPT } & PRECISE DAPT \\
\hline Age $>75$ years & -2 & Age \\
\hline Age 65 to $<75$ years & -1 & Creatinine clearance \\
\hline Age $<65$ years & 0 & Hemoglobin \\
\hline Current cigarette smoker & 1 & White blood cell count \\
\hline Diabetes mellitus & 1 & Previous spontaneous bleeding \\
\hline Ml at presentation & 1 & \\
\hline Prior $\mathrm{PCl}$ or prior $\mathrm{Ml}$ & 1 & \\
\hline Stent diameter $<3 \mathrm{~mm}$ & 1 & \\
\hline Paclitaxel-eluting stent & 1 & \\
\hline CHF or LVEF $<30 \%$ & 2 & \\
\hline Saphenous vein graft $\mathrm{PCl}$ & 2 & \\
\hline $\begin{array}{l}\text { Interpretation: a score of } \geq 2 \text { is associated with a } \\
\text { favorable benefit/risk ratio for prolonged DAPT while } \\
\text { a score of }<2 \text { is associated with an unfavorable } \\
\text { benefit/risk ratio }\end{array}$ & & $\begin{array}{l}\text { Interpretation: a sliding scale score is applied for each of the above variables, } \\
\text { and the sum of their values is applied to a nomogram to approximate 1-year } \\
\text { TIMI major bleeding and TIMI major or minor bleeding risk (see Fig. 2) }\end{array}$ \\
\hline $\begin{array}{l}\text { Validation: c-index for ischemia and bleeding of } 0.70 \\
\text { and } 0.68 \text {, respectively, in DAPT study patients, and } \\
0.64 \text { and } 0.64 \text {, respectively, in the PROTECT trial } \\
\text { validation cohort }\end{array}$ & & $\begin{array}{l}\text { Validation: c-index for out-of-hospital TIMI major or minor bleeding of } 0.73 \\
(95 \% \mathrm{Cl}: 0.61-0.85) \text { in the derivation cohort, } 0.70(0.65-0.74) \text { in the PLATO } \\
\text { trial validation cohort, and } 0.66(0.61-0.71) \text { in the BernPCI registry validation } \\
\text { cohort }\end{array}$ \\
\hline
\end{tabular}

CHF, congestive heart failure; DAPT, dual antiplatelet therapy; LVEF, left ventricular ejection fraction; MI, myocardial infarction; PCI, percutaneous coronary intervention.

\section{Duration of Dual Antiplatelet Therapy after Percutaneous Coronary Intervention}

Numerous studies have compared various durations of dual antiplatelet therapy (DAPT) in patients after PCI [1]. Although many involved second-generation stents, these studies have spanned different generations of stents which further complicates recommendations for the optimal duration of DAPT after PCI. Based on 5 randomized controlled trials [2-6], 3-6 months of DAPT was found to be noninferior to 12 months of DAPT in lowrisk patients (i.e., second-generation stents placed in patients with stable ischemic heart disease [SIHD]), in preventing stent thrombosis and ischemic events and had less GI bleeding, although these trials were individually underpowered to detect differences in stent thrombosis. On the other hand, in 6 randomized controlled trials [713] that used primarily second-generation drug-eluting stents, prolonged DAPT for up to 36 months beyond the initial 6- to 12-month treatment period was shown to reduce stent thrombosis and ischemic events at the expense of increased major nonfatal bleeding. Compared with a standard therapy of 6-12 months, an additional 18-36 months of DAPT after DES led to an absolute reduction in late stent thrombosis and ischemic complications (pri- marily spontaneous MI) of $1-2 \%(\mathrm{RR} 0.78, p=0.001)$ at the tradeoff on an absolute increase of $1 \%$ in bleeding complications (RR 1.73, $p=0.004$ ) [14]. Based on these studies and meta-analyses, the current class I guidelines for DAPT in patients who have undergone DES placement are a minimum of 6 months for those receiving PCI in the setting of SIHD and in those with PCI for ACS are a minimum of 12 months [1]. Recent trials regarding the use of ultra-short 1-month duration DAPT after singlevessel PCI for SIHD have shown noninferiority of DES to bare metal stents $[15,16]$. Ultra-short-duration DAPT may be a consideration in some patients, but future studies directly comparing ultra-short DAPT duration to standard DAPT therapy are needed. Given the challenges in weighing the benefits and risks of prolonged DAPT, several investigators have developed risk scores to help the clinician weigh the risk/benefit ratio of ischemic events compared with bleeding, including the DAPT score [17] and PRECISE DAPT [18]. A high score indicates that the ischemic risk likely outweighs the risk of major bleeding. Factors that contribute to high-risk DAPT and PRECISE DAPT scores are shown in Table 1 and Figure 1. After completion of the minimum required DAPT, the physician should engage the patient in a process of shared decision-making and discuss the hazards 


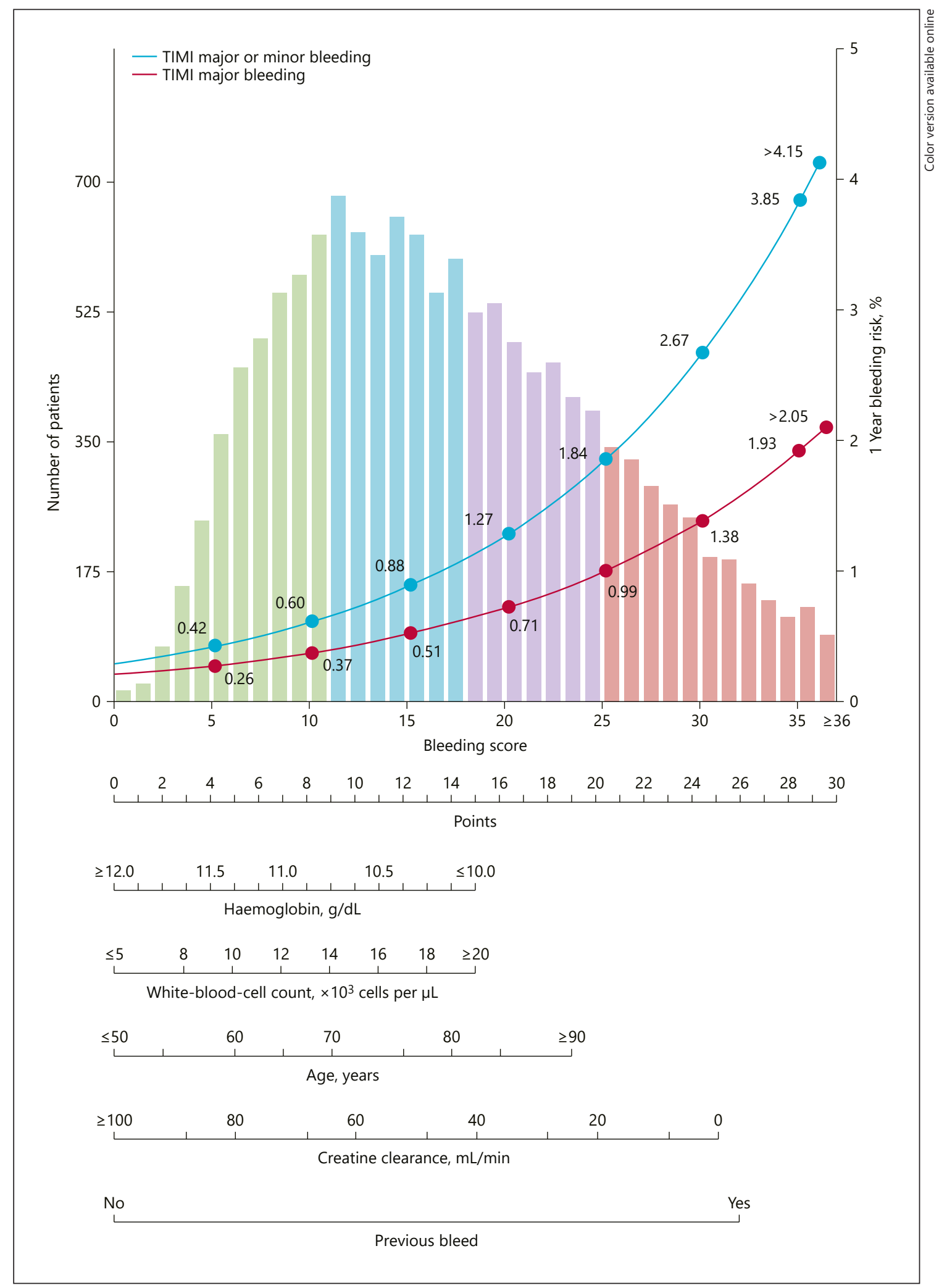

Fig. 1. Nomogram for bleeding risk calculation with PRECISE DAPT [18]. 
of bleeding and stent thrombosis/ischemic event risk and decide jointly if continuation of DAPT is of value.

In the case of the above patient who had a GI bleed 1 year after a newer generation DES for an ACS, the riskbenefit consideration would likely not favor continuation of DAPT and instead suggest continuation of antiplatelet monotherapy only. The patient does not have any increased risk factors for stent thrombosis or other ischemic risks and is at increased future bleeding risk due to his recent GI bleed. Here, the physician would need to consider which antiplatelet agent to resume, that is, aspirin or clopidogrel. There is no guidance in this regard, and below we review available information and considerations.

\section{Mechanisms of Antiplatelet Therapy and Relevance to Gastrointestinal Injury}

\section{Aspirin}

As first described by Vane [19] in 1971, aspirin blocks the production of prostaglandins. Cyclooxygenase is the rate-limiting step of prostaglandin and thromboxane synthesis, and aspirin nonspecifically and irreversibly inhibits cyclooxygenase by acetylating serine $516[19,20]$. Aspirin inhibits the formation of thromboxane $A_{2}$ in platelets and inhibits autoactivation of surface thromboxane receptors which are required for the activation of glycoprotein 2b/3a (GP 2b/3a) [21]. Aspirin also induces nitrous oxide and modulates the transcription factor complex NF-kB both of which play a role in reducing inflammation. Aspirin and other nonsteroidal anti-inflammatory drugs have both topical and systemic mechanisms that promote gastric or duodenal ulcer formation. Aspirin has a pKa of 3.50 and is not ionized in the acidic gastric lumen and can be absorbed across the $\mathrm{pH}$-neutral gastric mucosa where it becomes ionized and trapped temporarily in gastric mucosal cells [22], causing local damage. Systemic inhibition of cyclooxygenase, including in the gastric mucosa, inhibits the conversion of arachidonic acid to prostaglandin G2 which is later converted to prostaglandin $\mathrm{H} 2$ and then to prostaglandin E2. Prostaglandins increase local blood flow and increase synthesis and secretion of gastric mucus and bicarbonate. These topical and systemic effects, especially in combination with other factors that increase gastric acid secretion such as corticosteroid use, multiple NSAIDs, and age, ultimately result in a weakened mucosal barrier and a propensity for ulcer formation [23]. Once an ulcer has developed, the antiplatelet effects of aspirin increase the risk of bleeding. Efforts are underway to develop a safer aspirin
- a lipid-aspirin complex - that may reduce endoscopic GI ulceration compared with immediate-release aspirin and have better bioavailability and more consistent antiplatelet effects than enteric-coated aspirin [24, 25].

\section{Clopidogrel}

The formation of a stable platelet plug is dependent on the cross linking of pairs of platelet GP 2b/3a with fibrin. Clopidogrel is a thienopyridine antiplatelet agent which selectively and irreversibly inhibits ADP activation of the GP $2 b / 3 a$ complex by forming a disulfide bridge at the ADP-binding site on the $\mathrm{P} 2 \mathrm{Y}_{12} \mathrm{G}$ protein-coupled receptor [26]. Clopidogrel is a prodrug and is converted to its active metabolite in the liver through the cytochrome P450 system, including the 2C19 isoenzyme [27]. Clopidogrel has no topical effect on gastric mucosa, and this has been confirmed endoscopically. However, the antiplatelet effects of clopidogrel can predispose patients with gastric ulcers to bleeding, and there are some animal studies suggesting that clopidogrel delays gastric ulcer healing by inhibiting proangiogenic growth factors including vascular endothelial growth factor [28].

Therefore, just based on mechanism of action, it would seem that theoretically clopidogrel may be preferred in a patient who has experienced GI (especially upper) bleeding as aspirin not only increases bleeding when it occurs but is also ulcerogenic. While prasugrel and ticagrelor are also approved for the treatment of acute coronary syndrome, both have a higher incidence of major bleeding compared with clopidogrel (prasugrel $2.4 \%$ vs. clopidogrel $1.8 \%, p 0.03$; ticagrelor $4.5 \%$ vs. clopidogrel $3.8 \%, p$ $0.03)[29,30]$, and studies with monotherapy of these agents are just starting to emerge. Direct comparisons between aspirin and clopidogrel however exist and hence can provide some additional guidance in regard to which antiplatelet agent to use as monotherapy in the abovepresented scenario.

\section{Comparison of Aspirin and Clopidogrel for the Secondary Prevention of Cardiac Events}

The largest head-to-head comparison of aspirin and clopidogrel was the Clopidogrel Versus Aspirin in Patients at Risk of Ischemic Events (CAPRIE) trial, an international randomized double-blinded trial of high-risk patients with recent ischemic stroke, MI, or symptomatic peripheral artery disease, comparing 9,546 patients assigned to aspirin $325 \mathrm{mg}$ daily with 9,553 patients assigned to clopidogrel $75 \mathrm{mg}$ daily. Clopidogrel was superior to 
aspirin in reducing the primary endpoint of stroke, $\mathrm{MI}$, or vascular death (absolute event rate of 5.83\% for aspirin vs. $5.32 \%$ for clopidogrel, $p=0.043$ ), while there was no significant difference in the mortality rate $(3.11 \%$ vs. $3.05 \%$; $p=0.71)$. There was a lower rate of hospitalization for ischemia or bleeding in the clopidogrel arm (12.4\% vs. $13.6 \% ; p=0.018)$ [31]. Subgroup analyses showed that clopidogrel might be of greatest benefit for high-risk secondary-prevention patients, such as those with diabetes [32]. Although these results are statistically significant, the absolute difference in the trial overall is modest, and historically aspirin and clopidogrel have been considered to have similar efficacy and strength of recommendation in guidelines. Aspirin may in general have been preferred partially due to cost effectiveness; however, now that clopidogrel is generic, this may be less of a consideration.

\section{Incidence of Primary Gastrointestinal Event in Patients on Antiplatelet Therapy}

As previously discussed, aspirin increases the risk of peptic ulcer disease and GI bleeding by both topical and systemic mechanisms. Clopidogrel increases the risk of bleeding in a patient with an already established gastric ulcer and potentially impairs ulcer healing but does not have the same incidence of primary or recurrent ulcer formation after healing. The CAPRIE trial (1996) showed the incidence of any GI bleeding $(2.66 \%$ vs. $1.99 \% p<$ $0.05)$ and severe upper GI bleeding $(0.7 \%$ vs. $0.5 \% p<$ 0.05 ) was significantly higher in patients randomized to aspirin $325 \mathrm{mg}$ compared with clopidogrel and led to a higher rate of medication cessation $(0.93 \%$ vs. $0.52 \%$; $p<$ 0.05). 75-100 mg aspirin is currently the recommended and most commonly used dose in the setting of coronary artery disease. Small volunteer studies have shown that higher-dose (300-325 mg) aspirin is associated with increased mucosal damage compared with low-dose (75$100 \mathrm{mg}$ ) aspirin [33-36]. The ADAPTABLE Study is soon to be presented at ACC and may provide additional guidance on optimal dosing of aspirin.

\section{Medical Therapy for Ulcer-Associated Gastrointestinal Bleed}

After initial stabilization and management of an ulcerassociated bleed, patients should be tested and treated (when testing is positive) for $H$. pylori infections. Patients with a history of GI bleeding are at high risk for recurrent bleeding. Prophylactic therapy with a gastroprotective agent is generally indicated, and PPIs have been shown in multiple studies and meta-analysis to be superior to other agents including H2-receptor antagonists for the primary and secondary prevention of ulceration and bleeding [37-40]. As such, the American College of Gastroenterology guidelines currently recommend long-term PPI therapy for patients with a history of bleeding ulcers related to antiplatelet therapy [41]. The American College of Cardiology/American Heart Association (ACC/AHA) guidelines also recommend the use of PPIs in patients on DAPT who have a history of GI bleeding (class I recommendation) and in patients at risk for GI bleed including those on oral anticoagulant therapy, female sex, advanced age, low body weight, chronic kidney disease, diabetes mellitus, anemia, and nonsteroidal anti-inflammatory medications (class IIa recommendation) [42-45].

\section{Safety of Concomitant Antiplatelet and Gastroprotective Therapy with Proton Pump Inhibitors}

There are conflicting data about the importance of the interaction between PPIs and antiplatelet agents. Cytochrome P450 2C19 plays a key role in the metabolism of both clopidogrel and PPIs, and competitive inhibition of this enzyme may decrease clopidogrel activation. Inhibition of clopidogrel activation may be clinically important since patients with less-active 2C19 alleles have impaired platelet inhibition on clopidogrel and may be at higher risk of cardiovascular events [46, 47]. Initial laboratory studies indeed demonstrated decreased platelet inhibition and lower serum clopidogrel metabolites when clopidogrel was given in combination with PPIs [48]. Gilard et al. [49] evaluated patients on aspirin and clopidogrel and found that omeprazole significantly decreased the platelet inhibitory effect of clopidogrel. Subsequent studies have suggested that decreased antiplatelet activity may not be a PPI class effect with studies showing that omeprazole and esomeprazole may be worse than other PPIs, but these results have not been consistent [50,51]. Furthermore, even with omeprazole, taking clopidogrel and omeprazole $12 \mathrm{~h}$ apart may mitigate their interaction [52]. Most importantly, there is no clear evidence that these surrogate outcome markers are associated with adverse clinical outcomes [53]. Several large meta-analyses of retrospective and observational studies showed that patients on DAPT after PCI have higher major adverse cardiac events; however, there were no major adverse cardiovascular events 
when pooling data only from randomized controlled trials $[54,55]$. This dichotomy is likely the result of the increased medical complexity of patients who are prescribed PPIs [56]. The COGENT study which randomized 3,873 subjects on DAPT to omeprazole or placebo reported that the GI event rate including overt bleeding was significantly lower in the omeprazole arm, and the cardiac event rate was not different between the arms. Unfortunately, the study was terminated earlier than the planned 5,000 subjects due to sponsor losing funding [57]. The COMPASS trial was a $3 \times 2$ partial factorial, multicenter, doubleblind, randomized placebo-controlled trial evaluating patients with stable atherosclerotic vascular disease. Participants were randomized to low-dose rivaroxaban with or without low-dose aspirin. All participants without a clinical indication for PPI (64\%) were randomized to receive either pantoprazole $40 \mathrm{mg}$ or placebo. There was no statistically significant difference in total upper GI events; however, there was a significant difference in overt bleeding of gastroduodenal origin confirmed by endoscopy or radiography in those who received PPI therapy $(0.2 \%$ vs. $0.4 \%$; HR $0.52 ; p 0.03$ ). The authors concluded that the routine use of PPIs in patients on low-dose anticoagulation and/or aspirin for stable cardiovascular disease did not reduce upper GI events but may reduce bleeding from gastroduodenal lesions [58].

As with clopidogrel, there is evidence for the interaction between aspirin and PPIs which may compromise the efficacy of aspirin [59-61]. After correcting for baseline risk imbalances and the differences, however, there is no significant difference in clinical outcomes [62]. Histamine $(\mathrm{H} 2)$ receptor antagonists also increase gastric $\mathrm{pH}$ but are not associated with increased cardiovascular risk [63]. Based on available evidence, there seems to be a mechanistic basis that would support that antiplatelet therapy efficacy may be affected by concomitant therapy with PPIs, but this has not translated to an increased risk for adverse cardiovascular outcomes in clinical studies. Given that clinical trials cannot inform the risk at an individual patient level, it would be prudent for the clinician to use concomitant PPI therapy only when clearly needed as suggested in the guidelines.

\section{Comparison of Antiplatelet Therapies after GI Bleeding}

There are small randomized studies suggesting mortality benefit of resuming low-dose aspirin after upper or lower GI bleeding $[64,65]$. Several studies have sought to compare aspirin with other antiplatelets for primary and secondary cardiac and cerebrovascular prevention in patients with GI bleeding; however, most of these studies have been small. Chan et al. [66] randomized 320 patients to $75 \mathrm{mg}$ clopidogrel daily without PPI or aspirin $80 \mathrm{mg}$ and esomeprazole $20 \mathrm{mg}$ daily after an 8-week course of treatment for $H$. pylori-negative aspirin-induced peptic ulcer disease and found that patients assigned to clopidogrel had a higher bleeding rate; however, the study results are difficult to interpret given that patients in the clopidogrel arm were intentionally not given a PPI after randomization. A smaller study by Ng et al. [67] randomized 129 patients to clopidogrel with PPI or aspirin with PPI and found no difference in bleeding or treatment success rates. Hence, currently, there are only suboptimal data reporting on the comparison between antiplatelet strategies after GI bleeding.

\section{Summary and Our Recommendations}

The effectiveness of antiplatelet therapy for the secondary prevention of cardiovascular events has been very well documented. However, inherent to the mechanism of action, all of these antiplatelet agents increase the risk of bleeding. Addressing the choice of antiplatelet therapy for our patient with an aspirin-induced bleeding GI ulcer lies in balancing cardiovascular benefits with GI bleeding risks. Aspirin and clopidogrel appear to have similar efficacy for the prevention of coronary events with data perhaps suggesting that clopidogrel may have somewhat greater benefit in higher risk secondary prevention. Therefore, if from a cardiovascular standpoint there is equipoise, then the decision lies with preventing further or recurrent GI complications and addressing drug interactions. Mechanistically, aspirin would seem to have a higher risk of ulcer recurrence and bleeding due to topical effects and systemic prostaglandin inhibition. Head-to-head trial data in patients without a history of GI bleeding showed that aspirin has a higher primary GI bleeding rate compared with clopidogrel but used a higher dose of aspirin $(325 \mathrm{mg})$ than what we would currently recommend (75-100 $\mathrm{mg}$ ) for cardiovascular protection [30]. Even so, clopidogrel had greater efficacy than $325 \mathrm{mg}$ aspirin in CAPRIE, and it would be reasonable to assume that it would have superior efficacy to $81 \mathrm{mg}$ aspirin - however, this has not been studied. While the GI bleeding risk of $81 \mathrm{mg}$ aspirin is lower than the higherdose aspirin in the CAPRIE trial, clopidogrel likely remains a better choice with respect to the incidence of GI bleeding. 


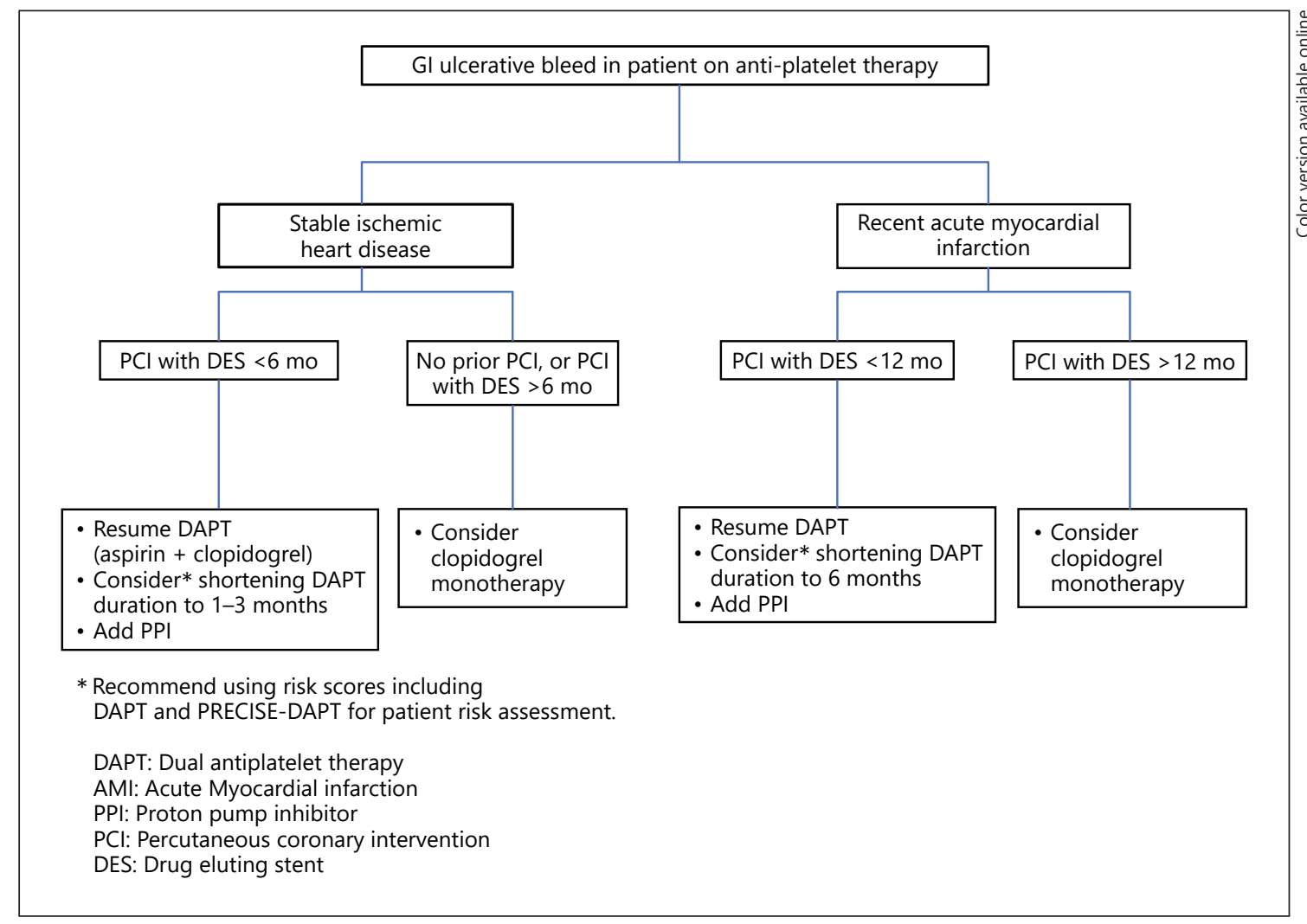

Fig. 2. Gastrointestinal (GI) bleed in a patient on antiplatelet therapy. ${ }^{*}$ Recommend using risk scores DAPT and PRECISE DAPT for patient risk assessment.

The American College of Gastroenterology guidelines currently recommend long-term PPI therapy for all patients with a history of bleeding ulcers (not just for those on aspirin). The concern for PPI-clopidogrel and PPIaspirin interaction from laboratory and observational studies has not been supported by randomized trials. Therefore, it is likely that the overall clinical significance of the interaction between various PPIs and antiplatelet agents is small, and longer-term randomized trials would be needed to determine if there is indeed a clinically relevant adverse drug-drug interaction.

Therefore, based on available clinical evidence including the mechanistic association between aspirin and GI ulcers, the likely superior efficacy of clopidogrel, and the lack of clear clinical implications from concomitant PPI use, we would recommend that patients with upper GI bleeding from an ulcer who need single antiplatelet therapy be treated preferentially with clopidogrel. It would be reasonable to use a PPI as well (Fig. 2).

\section{Conflict of Interest Statement}

Dr. Deepak L. Bhatt discloses the following relationships - Advisory Board: Cardax, CellProthera, Cereno Scientific, Elsevier Practice Update Cardiology, Janssen, Level Ex, Medscape Cardiology, MyoKardia, Novo Nordisk, PhaseBio, PLx Pharma, and Regado Biosciences; Board of Directors: Boston VA Research Institute, Society of Cardiovascular Patient Care, and TobeSoft; Chair: American Heart Association Quality Oversight Committee; Data Monitoring Committees: Baim Institute for Clinical Research (formerly Harvard Clinical Research Institute, for the PORTICO trial, funded by St. Jude Medical, now Abbott), Cleveland Clinic (including for the ExCEED trial, funded by Edwards), Contego Medical (Chair, PERFORMANCE 2), Duke Clinical Research Institute, Mayo Clinic, Mount Sinai School of Medicine (for the ENVISAGE trial, funded by Daiichi Sankyo), and Population Health Research Institute; honoraria: American College of Cardiology (Senior Associate Editor, Clinical Trials and News, ACC.org; Vice-Chair, ACC Accreditation Committee), Baim Institute for Clinical Research (formerly Harvard Clinical Research Institute; RE-DUAL PCI clinical trial steering committee funded by Boehringer Ingelheim; AEGIS-II executive committee funded by CSL Behring), Belvoir Publications (Editor in Chief, Harvard Heart Letter), Canadian Medical and Surgical Knowledge Translation Research 
Group (clinical trial steering committees), Duke Clinical Research Institute (clinical trial steering committees, including for the PRONOUNCE trial, funded by Ferring Pharmaceuticals), HMP Global (Editor in Chief, Journal of Invasive Cardiology), Journal of the American College of Cardiology (Guest Editor; Associate Editor), K2P (Co-Chair, interdisciplinary curriculum), Level Ex, Medtelligence/ReachMD (CME steering committees), MJH Life Sciences, Population Health Research Institute (for the COMPASS operations committee, publications committee, steering committee, and USA national co-leader, funded by Bayer), Slack Publications (Chief Medical Editor, Cardiology Today's Intervention), Society of Cardiovascular Patient Care (Secretary/Treasurer), and WebMD (CME steering committees); others: Clinical Cardiology (Deputy Editor), NCDR-ACTION Registry Steering Committee (Chair), and VA CART Research and Publications Committee (Chair); research funding: Abbott, Afimmune, Amarin, Amgen, AstraZeneca, Bayer, Boehringer Ingelheim, Bristol-Myers Squibb, Cardax, Chiesi, CSL Behring, Eisai, Ethicon, Ferring Pharmaceuticals, Forest Laboratories, Fractyl, HLS Therapeutics, Idorsia, Ironwood, Ischemix, Janssen, Lexicon, Lilly, Medtronic, MyoKar- dia, Novo Nordisk, Owkin, Pfizer, PhaseBio, PLx Pharma, Regeneron, Roche, Sanofi, Synaptic, and The Medicines Company; royalties: Elsevier (Editor, Cardiovascular Intervention: A Companion to Braunwald's Heart Disease); site co-investigator: Abbott, Biotronik, Boston Scientific, CSI, St. Jude Medical (now Abbott), and Svelte; trustee: American College of Cardiology; unfunded research: FlowCo, Merck, and Takeda.

\section{Funding Sources}

No funding was provided for this review article.

\section{Author Contributions}

Stephen Pickett was the primary author and received specific guidance and feedback from each of the other listed authors during the authorship of this review article.

\section{References}

1 Levine GN, Bates ER, Bittl JA, Brindis RG, Fihn SD, Fleisher LA, et al. 2016 ACC/AHA guideline focused update on duration of dual antiplatelet therapy in patients with coronary artery disease. J Am Coll Cardiol. 2016; 68(10):1082-115.

2 Colombo A, Chieffo A, Frasheri A, Garbo R, Masotti-Centol M, Salvatella N, et al. Secondgeneration drug-eluting stent implantation followed by 6- versus 12-month dual antiplatelet therapy: the SECURITY randomized clinical trial. J Am Coll Cardiol. 2014;64: 2086-97.

3 Gwan HC, Hahn JY, Park KW, Song YB, Chae $\mathrm{IH}$, Lim DS, et al. Six-month versus 12-month dual antiplatelet therapy after implantation of drug-eluting stents: the efficacy of xience/ promus versus cypher to reduce late loss after stenting (EXCELLENT) randomized, multicenter study. Circulation. 2012;125:505-13.

4 Kim BK, Hong MK, Shin DH, Nam CM, Kim JS, Ko YG, et al. A new stratedy for discontinuation of dual antiplatelet therapy: the RESET Trial (real safety and efficacy of 3-month dual antiplatelet therapy following endeavor zotarolimus-eluting stent implantation). J Am Coll Cardiol. 2012;60:1340-8.

5 Feres F, Costa RA, Abizaid A, Leon MB, Marin-Neto JA, Botelho RV, et al. Three versus twelve months of dual antiplatelet therapy after zotarolimus eluting stents: the OPTIMIZE randomized trial. JAMA. 2013;310: 2510-22.

6 Schulz-Schüpke S, Byrne RA, Ten Berg JM, Neumann FJ, Han Y, Adriaenssens T, et al. ISAR-SAFE: a randomized, double-blind, placebo-controlled trial of 6 versus 12 months of clopidogrel therapy after drug-eluting stenting. Eur Heart J. 2015;36:1252-63.
7 Mauri L, Kereiakes DJ, Yeh RW, Driscoll-Shempp P, Cutlip DE, Steg PG, et al. Twelve or 30 months of dual antiplatelet therapy after drug-eluting stents. N Engl J Med. 2014;371: 2155-66.

8 Park SJ, Park DW, Kim YH, Kang SJ, Lee SW, Lee CW, et al. Duration of dual antiplatelet therapy after implantation of drug-eluting stents. N Engl J Med. 2010;362:1374-82.

9 Valgimigli M, Campo G, Monti M, Vranckx P, Percoco G, Tumscitz C, et al. Short- versus long-term duration of dual antiplatelet therapy after coronary stenting: a randomized multicenter trial. Circulation. 2013;125: 2015-26.

10 Collet J-P, Silvain J, Barthélémy O, Rangé G, Cayla G, Van Belle E, et al. Dual-antiplatelet treatment beyond 1 year after drug-eluting stent implantation (ARTIC-Interruption): a randomized trial. Lancet. 2014;384:1577-85.

11 Gilard M, Barragan P, Noryani AAL, Noor HA, Majwal T, Hovasse T, et al. 6- versus 24-month dual antiplatelet therapy after implantation of drug-eluting stents in patients nonresistant to aspirin: the randomized, multicenter ITALIC trial. J Am Coll Cardiol. 2015;65:777-86.

12 Lee CW, Ahn JM, Park DW, Kang SJ, Lee SW, $\mathrm{Kim} \mathrm{YH}$, et al. Optimal duration of dual antiplatelet therapy after drug-eluting stent implantation: a randomized, controlled trial. Circulation. 2014;129:304-12.

13 Helft G, Steg PG, Le Feuvre C, Georges JL, Carrie D, Dreyfus X, et al. Stopping or continuing clopidogrel 12 months after drugeluting stent placement: the OPTIDUAL randomized trial. Eur Heart J. 2016;37:365-74.
14 Udell JA, Bonaca MP, Collet JP, Lincoff AM, Kereiakes DJ, Costa F, et al. Long-term dual antiplatelet therapy for secondary prevention of cardiovascular events in the subgroup of patients with previous myocardial infarction: a collaborative meta-analysis of randomized trials. Eur Heart J. 2016;37:390-9.

15 Valgimigli M, Patialiakas A, Thury A, McFadden E, Colangelo S, Campo G, et al. Zotarolimus-eluting versus bare-metal stents in uncertain drug-eluting stent candidates. J Am Coll Cardiol. 2015;65(8):805-15.

16 Urban P, Meredith IT, Abizaid A, Pocock SJ, Carrié D, Naber C, et al. Polymer-free drugcoated coronary stents in patients at high bleeding risk. N Engl J Med. 2015;373(21): 2038-47.

17 Yeh RW, Secemsky EA, Kereiakes DJ, Normand SL, Gershlick AH, Cohen DJ, et al. Development and validation of a prediction rule for benefit and harm of dual antiplatelet therapy beyond 1 year after percutaneous coronary intervention. JAMA. 2016;315(16): 1735-49.

18 Costa F, van Klaveren D, James S, Heg D, Räber L, Feres F, et al. Derivation and validation of the predicting bleeding complications in patients undergoing stent implantation and subsequent dual antiplatelet therapy (PRECISE-DAPT) score: a pooled analysis of indivual-patient datasets from clinical trials. Lancet. 2017;389:1025-34.

19 Vane JR. Inhibition of prostaglandin synthesis as a mechanism of action for aspirin-like drugs. Nat New Biol. 1971;231:232-5.

20 Roth GJ, Stanford N, Majerus PW. Acetylation of prostaglandin synthase by aspirin. Proc Natl Acad Sci U S A. 1975;72:3073-6. 
21 Hamberg M, Svensson J, Samuelsson B. Thromboxanes: a new group of biologically active compounds derived from prostaglandin endoperoxides. Proc Natl Acad Sci U S A. 1975;72:2994-8.

22 Smecuol E, Pinto Sanchez MI, Suarez A, Argonz JE, Sugai E, Vazquez H, et al. Low-dose aspirin affects the small bowel mucosa: results of a pilot study with a multidimensional assessment. Clin Gastroenterol Hepatol. 2009; 7:524-9.

23 Laine L. Review article: gastrointestinal bleeding with low-dose aspirin- what's the risk? Aliment Pharmacol Ther. 2006;24(6):897908.

24 Bhatt DL, Grosser T, Dong JF, Logan D, Jeske W, Angiolillo DJ, et al. Enteric coating and aspirin nonresponsiveness in patients with type 2 diabetes mellitus. J AM Coll Cardiol. 2017;69(6):603-12.

25 Cryer B, Bhatt DL, Lanza FL, Dong JF, Lichtenberger LM, Marathi UK. Low-dose aspirin-induced ulceration is attenuated by aspirin-phosphatidylcholine: a randomized clinical trial. Am J Gastroenterol. 2011;106(2): 272-7.

26 Savi P, Heilmann E, Nurden P, Laplace M-C, Bihour C, Kieffer G, et al. Clopidogrel: an antithrombotic drug acting on the ADP-dependent activation pathway of human platelets. Clin Appl Thromb Hemost. 1996;2(1):35-42.

27 Hagihara K, Kazui M, Kurihara A, Yoshiike $\mathrm{M}$, Honda $\mathrm{K}$, Okazaki O, et al. A possible mechanism for the differences in efficiency and variability of active metabolite formation from thienopyridine antiplatelet agents, prasugrel and clopidogrel. Drug Metab Dispos. 2009;37:2145-52.

28 Luo JC, Peng YL, Chen TS, Huo TI, Hou MC, Huang HC, et al. Clopidogrel inhibits angiogenesis of gastric ulcer healing via downregulation of vascular endothelial growth factor receptor 2. J Formos Med Assoc. 2016;115: 764-72.

29 Wiviott SD, Braunwald E, McCabe CH, Montalescot G, Ruzyllo W, Gottlieb S, et al. Prasugrel versus clopidogrel in patients with acute coronary syndromes. N Engl J Med. 2007;357: 2001-15.

30 Wallentin L, Becker RC, Budaj A, Cannon CP, Emanuelsson $\mathrm{H}$, Held C, et al. Ticagrelor versus clopidogrel in patients with acute coronary syndromes. N Engl J Med. 2009;361: 1045-57.

31 Bhatt DL, Hirsch AT, Ringleb PA, Hacke W, Topol EJ. Reduction in the need for hospitalization for recurrent ischemic events and bleeding with clopidogrel instead of aspirin. CAPRIE investigators. Am Heart J. 2000; 140(1):67-73.

32 Hirsh J, Bhatt DL. Comparative benefits of clopidogrel and aspirin in high-risk patient populations: lessons from the CAPRIE and CURE studies. Arch Intern Med. 2004; 164(19):2106-10
33 Cole AT, Hudson N, Liew LC, Murray FE, Hawkey CJ, Heptinstall S. Protection of human gastric mucosa against aspirin-enteric coating or dose reduction? Aliment Pharmacol Ther. 1999;13:187-93.

34 Dammann HG, Burkhardt F, Wolf N. Enteric coating of aspirin significantly decreases gastroduodenal mucosal lesions. Aliment Pharmacol Ther. 1999;13:1109-14.

35 Mehta SR, Tanguay JF, Eikelboom JW, Jolly SS, Joyner CD, Granger CB, et al. Doubledose versus standard-dose clopidogrel and high-dose versus low-dose aspirin in individuals undergoing percutaneous coronary intervention for acute coronary syndromes (CURRENT OASIS 7): a randomised factorial trial. Lancet. 2010;376(9748):1233-43.

36 Antiothrombotic Trialists' Collaboration. Collaborative meta-analysis of randomised trials of antiplatelet therapy for prevention of death, myocardial infarction, and stroke in high risk patients. BMJ. 2002;324(7329):7186.

37 Ng FH, Lam KF, Wong SY, Chang CM, Lau YK, Yuen WC, et al. Upper gastrointestinal bleeding in patients with aspirin and clopidogrel co-therapy. Digestion. 2008;77:173-7.

$38 \mathrm{Ng} \mathrm{FH}$, Wong SY, Lam KF, Chu WM, Chan $\mathrm{P}$, Ling $\mathrm{YH}$, et al. Famotidine is inferior to pantoprazole in preventing recurrence of aspirin-related peptic ulcers or erosions. Gastroenterology. 2010;138:82-8.

$39 \mathrm{Ng} \mathrm{FH}$, Tunggal P, Chu WM, Lam KF, Li A, Chan K, et al. Esomeprazole compared with famotidine in the prevention of upper gastrointestinal bleeding in patients with acute coronary syndrome or myocardial infarction. Am J Gastroenterol. 2012;107:389-96.

40 Gisbert JP, González L, Calvet X, Roqué M, Gabriel R, Pajares JM. Proton pump inhibitors versus $\mathrm{H} 2$-antagonists: a meta-analysis of their efficacy in treating bleeding peptic ulcer. Aliment Pharmacol Ther. 2001;15:917-26.

41 Laine L, Jensen DM. Management of patients with ulcer bleeding. Am J Gastroenterol. 2012;107:345-61.

42 Subherwal S, Bach RG, Chen AY, Gage BF, Rao SV, Newby LK, et al. Baseline risk of major bleeding in non-ST-segment-elevation myocardial infarction: the CRUSADE (can rapid risk stratification of unstable angina patients suppress adverse outcomes with early implementation of the ACC/AHA guidelines) bleeding score. Circulation. 2009;119: 1873-82.

43 Moscucci M, Fox KA, Cannon CP, Klein W, López-Sendón J, Montalescot G, et al. Predictors of major bleeding in acute coronary syndromes: the global registry of acute coronary events (GRACE). Eur Heart J. 2003;24:181523.

44 Mehran R, Pocock SJ, Nikolsky E, Clayton T, Dangas GD, Kirtane AJ, et al. A risk score to predict bleeding in patients with acute coronary syndromes. J Am Coll Cardiol. 2010;55: 2556-66.
45 Binder RK, Lüscher TF. Duration of dual antiplatelet therapy after coronary artery stenting: where is the sweet spot between ischaemia and bleeding? Eur Heart J. 2015;36: 1207-11.

46 Mega JL, Close SL, Wiviott SD, Shen L, Hockett RD, Brandt JT, et al. Cytochrome p-450 polymorphisms and response to clopidogrel. N Engl J Med. 2009;360:354-62.

47 Hulot JS, Collet JP, Silvain J, Pena A, Bellemain-Appaix A, Barthélémy $\mathrm{O}$, et al. Cardiovascular risk in clopidogrel-treated patients according to cytochrome P450 2C19*2 lossof-function allele or proton pump inhibitor coadministration: a systemic meta-analysis. J Am Coll Cardiol. 2010;56:134-43.

48 Cuisset T, Frere C, Quilici J, Poyet R, Gaborit $\mathrm{B}, \mathrm{Bali} \mathrm{L}$, et al. Comparison of omeprazole and pantoprazole influence on a high $150-\mathrm{mg}$ clopidogrel maintenance dose: the PACA (Proton Pump Inhibitors And Clopidogrel Association) prospective randomized study. J Am Coll Cardiol. 2009;54:1149-53.

49 Gilard M, Arnaud B, Le Gal G, Abgrall JF, Boschat J. Influence of omeprazol on the antiplatelet action of clopidogrel associated to aspirin. J Thromb Haemost. 2006;4(11): 2508-9.

50 Siller-Matula JM, Spiel AO, Lang IM, Kreiner G, Christ G, Jilma B. Effects of pantoprazole and esomeprazole on platelet inhibition by clopidogrel. Am Heart J. 2009;157:148-5.

51 Frelinger AL, Lee RD, Mulford DJ, Wu J, Nudurupati S, Nigam A, et al. A randomized, 2-period, crossover design study to assess the effects of dexlansoprazole, lansoprazole, esomeprazole, and omeprazole on the steadystate pharmacokinetics and pharmacodynamics of clopidogrel in healthy volunteers. J Am Coll Cardiol. 2012;59(14):1304-11.

52 Kenngott S, Olze R, Kollmer M, Bottheim H, Laner A, Holinski-Feder E, et al. Clopidogrel and proton pump inhibitor (PPI) interaction: separate intake and a non-omeprazole PPI the solution? Eur J Med Res. 2010;15:220-4.

53 O'Donoghue ML, Braunwald E, Antman EM, Murphy SA, Bates ER, Rozenman Y, et al. Pharmacodynamic effect and clinical efficacy of clopidogrel and prasugrel with or without a proton-pump inhibitor: an analysis of two randomised trials. Lancet. 2009;374:989-97.

54 Bundhun PK, Teeluck AR, Bhurtu A, Huang WQ. Is the concomitant use of clopidogrel and proton pump inhibitors still associated with increased adverse cardiovascular outcomes following coronary angioplasty?: A systematic review and meta-analysis of recently published studies (2012-2016). BMC Cardiovasc Disord. 2017;17:3.

55 Huang B, Huang Y, Li Y, Yao H, Jing X, Huang $\mathrm{H}$, et al. Adverse cardiovascular effects of concomitant use of proton pump inhibitors and clopidogrel in patients with coronary artery disease: a systematic review and metaanalysis. Arch Med Res. 2012;43:212-24. 
56 Banerjee S, Weideman RA, Weideman MW, Little BB, Kelly KC, Gunter JT, et al. Effect of concomitant use of clopidogrel and proton pump inhibitors after percutaneous coronary intervention. Am J Cardiol. 2011;107:871-8.

57 Bhatt DL, Cryer BL, Contant CF, Cohen M, Lanas A, Schnitzer TJ, et al. Clopidogrel with or without omeprazole in coronary artery disease. N Engl J Med. 2010;363:1909-17.

58 Moayyedi P, Eikelboom JW, Bosch J, Connolly SJ, Dyal L, Shestakovska O, et al. Pantoprazole to prevent gastroduodenal events in patients receiving rivaroxaban and/or aspirin in a randomized, double-blind, placebo-controlled trial. Gastroenterology. 2019;157:40312.e5.

59 Vaduganathan M, Bhatt DL. Aspirin and proton-pump inhibitors: interpreting the interplay. Eur Heart J Cardiovasc Pharmacother. 2016;2:20-2.

60 Würtz M, Grove EL, Kristensen SD, Hvas AM. The antiplatelet effect of aspirin is reduced by proton pump inhibitors in patients with coronary artery disease. Heart. 2010;96: $368-71$.
61 Giraud MN, Sanduja SK, Felder TB, Illich PA, Dial EJ, Lichtenberger LM. Effect of omeprazole on the bioavailability of unmodified and phospholipid-complexed aspirin in rats. Aliment Pharmacol Ther. 1997;11:899-906.

62 Fortuna LA, Pawloski PA, Parker ED, Trower NK, Kottke TE. Proton pump inhibitor use by aspirin-treated coronary artery disease patients is not associated with increased risk of cardiovascular events. Eur Heart J Cardiovasc Pharmacother. 2016;2:13-9.

63 Charlot M, Grove EL, Hansen PR, Olesen JB, Ahlehoff O, Selmer C, et al. Proton pump inhibitor use and risk of adverse cardiovascular events in aspirin treated patients with first time myocardial infarcation: nationwide propensity score matched study. BMJ. 2011;342: d2690.
64 Chan FK, Leung Ki EL, Wong GL, Ching JY, Tse YK, Au KW, et al. Risks of bleeding recurrence and cardiovascular events with continued aspirin use after lower gastrointestinal hemorrhage. Gastroenterology. 2016;151(2): 271-7.

65 Sung JJ, Lau JY, Ching JY, Wu JC, Lee YT, Chiu PW, et al. Continuation of low-dose aspirin therapy in peptic ulcer bleeding. A randomized trial. Ann Intern Med. 2010;152:19.

66 Chan FK, Ching JY, Hung LC, Wong VW, Leung VK, Kung NN, et al. Clopidogrel versus aspirin and esomeprazole to prevent recurrent ulcer bleeding. N Engl J Med. 2005;352: $238-44$

$67 \mathrm{Ng} \mathrm{FH}$, Wong BC, Wong SY, Chen $\mathrm{WH}$, Chang CM. Clopidogrel plus omeprazole compared with aspirin plus omeprazole for aspirin-induced symptomatic peptic ulcers/ erosions with low to moderate bleeding/rebleeding risk - a single-blind, randomized controlled study. Aliment Pharmacol Ther. 2004;19:359-65. 